\title{
The Action of Cisapride on the Chronic Constipation of Paraplegia
}

\author{
N. R. Binnie, FRCSE, ${ }^{1}$ G. H. Creasey, FRCSE, ${ }^{1}$ P. Edmond, CBE, TD, \\ FRSCE, ${ }^{1}$ A. N. Smith, MD, FRCSE, FRSE ${ }^{2}$ \\ ${ }^{1}$ Spinal Injuries Unit, Edenhall Hospital, Musselburgh, UK. ${ }^{2}$ Department of \\ Surgery/Urology, Western General Hospital, Edinburgh, UK.
}

\begin{abstract}
Summary
Paraplegic patients have intractable constipation associated with prolonged colonic transit time. The agent Cisapride significantly reduced the colonic transit time from 7.7 days to 5.1 days. It also improved the intraluminal tone in the rectum, resulting in a significant reduction in maximal rectal capacity from $305.8 \mathrm{ml}$ to $224.3 \mathrm{ml}$. There was a reduction in residual urine volume from $51.5 \mathrm{ml}$ to $27.7 \mathrm{ml}$. The increased number of stools containing transit markers showed that intraluminal mixing was increased by cisapride. Faecal water remained unchanged. A side effect was retention of urine in one subject after sudden withdrawal of the drug but this was avoided by its gradual reduction over 2 days.
\end{abstract}

Key words: Paraplegia; Constipation; Colonic transit time; Cisapride.

Severe Spinal cord injury results in motor paralysis which is later complicated by bladder and bowel problems (Denny-Brown 1935; Connell 1963). The commonest bowel problem in the later phase is intractable constipation (Glick 1984). The release of acetylcholine (ACh) at the myenteric plexus by pharmacological means could be expected to stimulate colonic activity. The agent cisapride (Janssen Pharmaceutical Ltd) acts to stimulate gastrointestinal activity by releasing $\mathrm{ACh}$ at the myenteric plexus (Smout 1985). The present study investigates the effect of cisapride on colonic transit time and on rectal capacity in spinal injured subjects. The study was part of a wider project for which ethical permission was granted by the Lothian Health Board, Scotland in July 1985.

\section{Patients}

Ten patients with complete, traumatic spinal cord injury were studied. There were 9 males and 1 female with a mean age of 34.1 years (range 20-45 years). The level of cord injury varied from C4 to T10. The mean time since injury was 8.1 years (range 1-20 years). All subjects gave informed consent and were investigated while in the spinal injuries unit. During the study each patient acted as his/her own control. 


\section{Methods}

When patients entered the trial, the extent of their constipation was determined by first establishing their intestinal transit times. The 10 subjects were fasted for a control period of at least 8 hours before being given an intravenous injection of $10 \mathrm{mg}$ cisapride. Rectal capacity and pressure studies done in the control period were now repeated. After an interval of at least 48 hours the subject was commenced on oral cisapride $10 \mathrm{mg} 8$ hourly. This was taken for 48 hours before the transit times were repeated. The cisapride was continued until each transit time estimation was complete. At this time blood tests and residual urine volumes were repeated.

\section{Gastrointestinal transit time}

The Oro-Caecal Transit Time (OCT) was estimated using the oral lactulose and expired breath hydrogen method (Bond 1975). A sample of end expiratory breath is taken as a baseline level of breath hydrogen. The subject swallows $10 \mathrm{~g}$ of lactulose with a standard breakfast of $500 \mathrm{cal}$, having fasted for 8 hours. Thereafter the breath is sampled every 15 minutes until the rise in hydrogen due to the lactulose reaching the caecum is observed. The Oro-Anal Transit Time (OAT) is estimated using radio-opaque polythene markers and X-raying of the stools (Hinton 1969). This allows a reasonable measure of transit time and avoids unnecessary exposure of the subject to $\mathrm{X}$-rays. The Colonic-Transit Time (CTT) was calculated by subtracting the OCT from the OAT.

The method of stool collection was by manual rectal evacuation with the occasional spontaneous evacuation. A digital rectal examination was performed each morning after breakfast and any rectal contents were evacuated into the collection bag. The patients were divided into two groups of five subjects. The group with spinal lesions $\mathrm{C} 4$ to $\mathrm{C} 7$ had the rectal examination and evacuation performed by an attendant while the second group with lesions T3 to T10 were able to perform the examinations and evacuations themselves.

\section{Anal sphincter studies}

The functional Sphincter Length (SL) of the combined internal and external anal sphincter was recorded in increments of $1 \mathrm{~cm}$ together with the maximum resting pressure (MRP) (Varma 1984). The Recto-Anal Sphincteric Inhibitory Reflex (RSR) (Gowers 1877, Henry 1985) records the reflex induced fall in pressure due to the internal anal sphincter relaxing on rapid distention of the rectum with $50 \mathrm{ml}$ of air.

\section{Electrophysiological studies}

The integrity and latency of the Pudendo-Anal Reflex (PAR) (Smith 1984) involves a minor electrical stimulus over the dorsal genital nerve while recording from an anal plug electrode. Using this same anal plug electrode as a stimulating electrode, the integrity and latency of conduction in the spinal cord can be 
assessed by recording Somatosensory Cerebral Evoked Potentials (SSEP) with scalp electrodes (Lehmkull 1986).

\section{Proctometrogram}

The rectal capacity (MAXV) and rise in intraluminal pressure (MAXP) as changes in rectal volume are achieved is derived by this technique (Varma 1986). A large compliant rectal balloon is distended at a rate of 67 $\mathrm{ml} / \mathrm{min}$ while the pressure in the balloon is recorded by a second device. The point of spontaneous expulsion of the rectal balloon or the detection of autonomic dysreflexia is taken as being at maximal rectal capacity. The ratio of MAXV to MAXP (RATIO V/P) gives an indication of the distensibility of the rectum.

\section{Pulse rate and blood pressure}

These were recorded when intravenous cisapride was given and continued every 5 minutes for up to 30 minutes afterwards. The recordings were taken from the brachial pulse just proximal to the antecubital fossa with a Dynamap automatic pneumatic cuff recording device.

Blood count, urea electrolytes and liver function

These tests were carried out in the hospital laboratories in the normal way.

\section{Residual urine volume}

This was carried out in the subjects who did not have an indwelling catheter, both before and during administration of oral cisapride (RUV).

\section{Faecal water content}

The percentage water content $\left(\% \mathrm{H}_{2} \mathrm{O}\right)$ of the faeces was derived by weighing the samples before and after a freeze drying technique (Eastwood 1984).

\section{Transit marker dispersion}

The number of separate stools containing transit marker pellets (STM) was recorded for each subject, giving an indication of intraluminal mixing.

\section{Statistical analysis}

Statistical significance was determined by a $t$ test after logarithmic conversion of the data.

\section{Results}

The results are given in the Table. Figures 1, 2 and 3 show the results for colonic transit time, maximum rectal volume and the ratio of rectal volume to 
Table Results of investigations. Those measured before cisapride was taken orally are in the column termed 'Control' while those recorded with the effect of cisapride are in the column headed 'Cisapride'

\begin{tabular}{|c|c|c|}
\hline & Control & Cisapride \\
\hline \multicolumn{3}{|c|}{ Transit times } \\
\hline OCT & $3.4 \pm 1.4 \mathrm{hr}$ & $2.6 \pm 0.58 \mathrm{hr}$ \\
\hline OAT & $187.3 \pm 87.6 \mathrm{hr}$ & $125.0 \pm 77.0 \mathrm{hr}$ \\
\hline CTT & $185.0 \pm 86.3 \mathrm{hr}$ & $123.0 \pm 77.0 \mathrm{hr}$ \\
\hline \multicolumn{3}{|c|}{ Pressure and volume } \\
\hline SL & $3 \mathrm{~cm}$ & $3 \mathrm{~cm}$ \\
\hline MRP & $116 \pm 33 . \mathrm{cmH}_{2} \mathrm{O}$ & $125 \pm 28.8 \mathrm{cmH}_{2} \mathrm{O}$ \\
\hline RSR & $65 \pm 19.5 \mathrm{cmH}_{2} \mathrm{O}$ & $72.5 \pm 25.1 \mathrm{cmH}_{2} \mathrm{O}$ \\
\hline MAXV & $305.8 \pm 93.6 \mathrm{ml}$ & $224.3 \pm 55.4 \mathrm{ml}$ \\
\hline MAXP & $72.5 \pm 18.8 \mathrm{cmH}_{2} \mathrm{O}$ & $76 \pm 21.2 \mathrm{cmH}_{2} \mathrm{O}$ \\
\hline Ratio V/P & $4.3 \pm 1.4$ & $3.1 \pm 1.1$ \\
\hline RUV & $51.5 \pm 16.7 \mathrm{ml}$ & $27.7 \pm 8.4 \mathrm{ml}$ \\
\hline \multicolumn{3}{|c|}{ Electrophysiology } \\
\hline PAR & $37.1 \pm 4.6 \mathrm{~ms}$ & \\
\hline SSEP & Absent & Absent \\
\hline \multicolumn{3}{|l|}{ Faeces } \\
\hline${ }^{0} \mathrm{H}_{2} \mathrm{O}$ & $63.8 \pm 4.8$ & $64.3 \pm 6.3$ \\
\hline STM & $1.9 \pm 0.6$ & $3.1 \pm 1.6$ \\
\hline \multicolumn{3}{|c|}{ Cardiovascular } \\
\hline SYST & $112.5 \pm 15.7 \mathrm{mmHG}$ & $112 \pm 12.2 \mathrm{mmHG}$ \\
\hline DYAST & $64.5 \pm 19 \mathrm{mmHg}$ & $59 \pm 16.4 \mathrm{mmHG}$ \\
\hline HR & $77.2 \pm 9.7 / \mathrm{min}$ & $76.3 \pm 10.1 / \mathrm{min}$ \\
\hline
\end{tabular}

OCT $=$ Oro caecal transit time. OAT $=$ Oral anal transit time. CTT $=$ Colonic transit time. SL $=$ Anal Sphincter length . $\mathrm{MRP}=$ Maximum resting pressure. $\mathrm{RSR}=$ Recto sphincteric inhibitory reflex. MAXV and MAXP $=$ Maximum rectal volume and pressure. Ratio $\mathrm{V} / \mathrm{P}=$ Ratio of maximum rectal volume to maximum pressure. RUV = Residual urine volume. PAR = Pudendo anal reflex latency. SSEP = Somato sensory evoked potential. ${ }_{0}^{\circ} \mathrm{H}_{2} \mathrm{O}=$ Percentage water content. STM $=$ Stools containing transit markers. SYST and DYST $=$ Systolic and Dyastolic blood pressure. HR = Pulse rate.

rectal pressure. All three achieved statistical significance with $\mathrm{p}<0.001$, $\mathrm{p}<0.005$ and $\mathrm{p}<0.005$ respectively. The colonic transit time was reduced from 185 hours to 123 hours, the maximum rectal volume was reduced from $305 \mathrm{ml}$ to $224 \mathrm{ml}$ and the ratio of miximum rectal volume to maximum rectal pressure was reduced from 4.3 to 3.1. The faecal water remained unchanged. Stool mixing of markers was increased from 1.9 to 3.1 stools.

\section{Discussion}

The colon has an intrinsic myenteric nerve plexus which has a degree of spontaneous activity and causes autonomous colonic muscle activity (Christensen 1981). This myenteric plexus can also be stimulated by the extrinsic nerve supply of the colon (Bayliss 1900; Wood 1981). The constipation in spinal injury subjects may be due to interruption, at the spinal level, of the extrinsic nerve supply to the distal colon. The extrinsic parasympathetic nerve supply to 


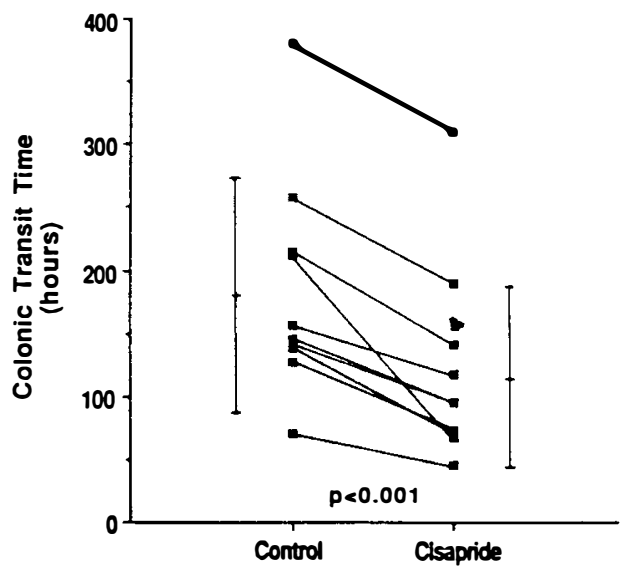

Figure 1 Colonic Transit Time measured in hours. The transit time before cisapride under 'Control' while transit time with the effect of the drug under 'Cisapride'

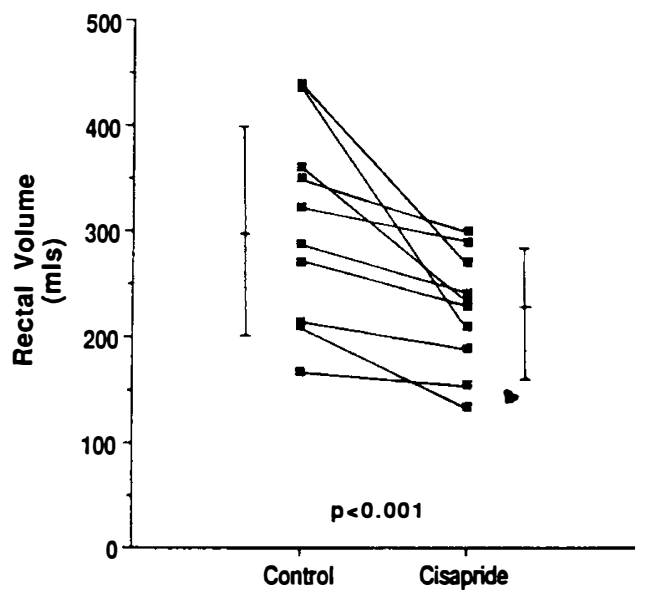

Figure 2 Maximum Rectal Volume or rectal capacity in $\mathrm{ml}$. The rectal volume before the drug was taken is under 'Control' while the rectal volume with the drug is under 'Cisapride'.

the distal colon emerges from the central nervous system with the anterior sacral roots $S 2,3$ and 4. Direct electrical stimulation of these sacral nerve roots has been shown to affect the pelvic colon and ano-rectal function (Varma and Binnie et al., 1986). As neuroprosthetic stimulation to increase the activity of the colon is not yet as appropriate as its use for bladder stimulation, a suitable pharmacological preparation capable of stimulating intestinal motility would have more immediate application. The agent cisapride is a synthetic substituted benzamide which has been shown to have a potent stimulation effect on isolated rabbit colonic smooth muscle, probably through a muscarinic receptor (Snape 1985). There is a similar effect on guinea pig ileum. Using binding studies for dopamine receptors on rat striatum and when tested against apomorphine 


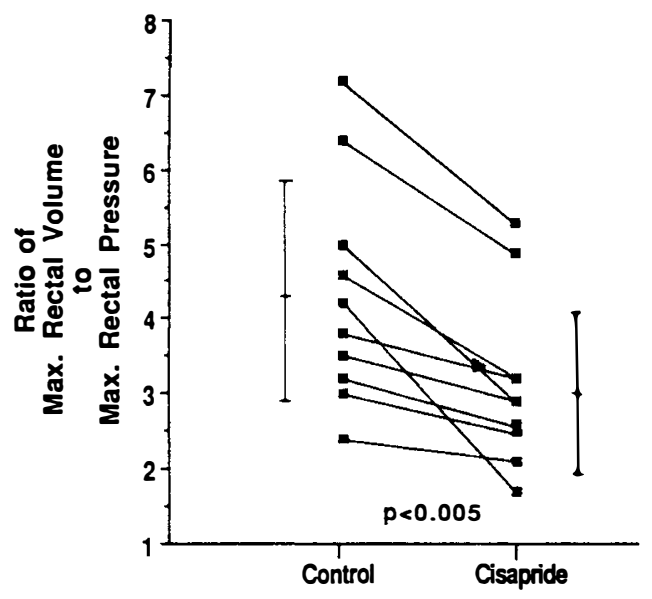

Figure 3 Ratio of Maximum Rectal Volume in ml over the Maximum Intraectal Pressure in centimetres of water at the point of maximum capacity.

induced vomiting in dogs, there was no anti-dopaminergic properties (VanNueten 1985). The effect on motor activity may be mediated in part by blocking type 2 serotonin receptors (Moriarty 1985) and the possible release of other gastrointestinal hormones (Koop 1986). The action of this agent has been studied in humans, on oesophageal motility (Wienbeck 1984; Corazziari 1985; Smout 1985). These authors have shown that this agent reduces gastro-oesophageal reflux by increasing the pressure in the region of the gastro-oesophageal junction. In gastric motility (Jian 1985; Thomforde 1985; Edwards 1987) cisapride stimulates gastric emptying. As a consequence of jejunal activity (Stacher 1986) and stimulation of colonic motility (Miller-Lissner 1985; Lee 1984; Lederer 1985) it is said to reduce transit time.

The present study shows that in spinal injured subjects cisapride significantly reduces both colonic transit time and the maximum rectal capacity. The intraluminal mixing of contents is increased, as detected by the increased dispersion of markers in stool collections. The faecal water content is little changed. The internal anal sphincter reflex relaxation caused by rectal distention is not inhibited by cisapride. There appeared to be no adverse effects on heart rate or blood pressure although there was a slight reduction in diastolic pressure. No side effects on parameters of full blood count, urea, electrolytes and liver function tests were noted. In the first patient, who normally emptied his bladder by suprapubic tapping, the unwanted side effect of acute retention of urine was noted on the morning after abrupt cessation of oral cisapride. This resolved after 1 day of intermittent catheterisation. In subsequent subjects the cisapride was tailed off at $10 \mathrm{mg}$ twice and $10 \mathrm{mg}$ once per day for 1 day each before stopping the drug completely. A reduction in residual volume while taking cisapride was noted in 7 of the remaining subjects but a more formal study would be required to determine the significance, if any, of this finding.

Regarding the long-term effects of cisapride, there are to date several subjects, including 2 from this study, who have taken the drug for periods in excess of 1 
year. The beneficial effects on colonic function are maintained and will be formally reported at a later date. We have not detected any deleterious long term effects of oral cisapride $10 \mathrm{mg}$ thrice daily on modalaties of blood pressure or heart rate, full blood count, urea, electrolytes and liver function tests. We did however record 1 case of retention of urine after abrupt cessation of the drug and we have subsequently recorded increased frequency of micturition in 3 subjects with incomplete spinal lesions being treated with cisapride for colonic transit problems. This increased frequency was troublesome in 1 female subject and was corrected by reducing the dosage of cisapride to $10 \mathrm{mg}$ twice per day.

\section{Acknowledgements}

Mr N. R. Binnie was supported by the Scottish Hospital Endownment Research Trust, Grant number 720 and an attachment to the Wolfson G.I. Research Laboratories, Western General Hospital, Edinburgh, EH4 2XU.

\section{References}

BAYLISS WM, STARLING EN 1900 The mass movements and the innervation of the large intestine. fournal of Physiology 26:107-118.

BOND JH, LEVITT MD 1975 Investigation of small bowel transit time in man utilizing pulmonary hydrogen measurements. Fournal of Laboratory and Clinical Medicine 85:546-555.

Christensen J 1981 Motility of the Colon. Chapter 14. Physiology of the Gastrointestinal Tract, Ed. Johnson LR. Raven Press, New York.

CONNELl AM, Frankel HL, Guttmann L 1963 The motility of the pelvic colon following complete lesions of the spinal cord. Paraplegia 1:93-115.

CORAZZIARI E, BONTEMPO I, ANZI F, et al. 1985 Effect of cisapride on esophageal motor activity before and af ter atropine administration. Gastroenterology 88:1355.

DENNY-BROWN D, RoBERTSON G, 1935 An investigation of the nervous control of defecation. Brain 58:256-310

EASTWOOD MA, BRYDON WG et al. 1984 Faecal weight and composition, serum lipids, and diet among subjects aged 18 to 80 years not seeking health care. American fournal of Clinical Nutrition 40:628-634.

EDWARDS CA, Holden S, BROWN C, et al. 1987 Effect of cisapride on the gastrointestinal transit of solid meal in normal human subjects. Gut 28:13-16.

Glick ME, Meshrinapour H et al. 1984 Colonic dysfunction in patients with thoracic spinal cord injury. Gastroenterology 86:287-294.

Gowers WR 1877 The automatic action of the sphincter ani. Proceedings of the Royal Society London 26:77-84.

HENRY MM, SNOOKS SJ et al. 1985 Investigation of disorders of the anorectum and colon. Annals $R$ Col. Surg. Eng. 67:355-360.

Hinton JM, LENNARD-Jones JE, Young AC 1969. A new method for measuring gut transit using radio-opaque markers. Gut 10:842:7.

Jian R, DuCrot F, Piedeloup C, et al. 1985 Measurement of gastric emptying in dyspeptic patients: effect of a new gastrokinetic agent (cisapride). Gut 26:352-358.

KoOP H, MonNikes H et al. 1986 Effect of the prokinetic drug cisapride on gastrointestinal hormone release. Scandinavian fournal of Gastroenterology 21:907-1013.

LEDERER PC, ElLERMAN A, SCHMidT H, et al. 1985 Effect of cisapride on sigmoid motility in healthy subjects and in diabetic enteropathy (DE) with constipation. 1985. Gastroenterology 88:1468.

LEE KY, CHEY WY, YOU CH, et al. 1984 Effect of cisapride on the motility of gut in dogs and colonic transit time in dogs and humans. Gastroenterology 86:1157.

LehMKull LD, DimitriJeVIC MR, ZiDAR J 1986 Lumbosacral evoked potentials (LSEP) and cortical somatosensory evoked potentials (SEP) in patients with a cauda equina lesion. Paraplegia 24:46.

MILLER-LISSNER SA 1985 Cisapride in chronic constipation and laxative abuse. Gastroenterology 88:1510. 
Moriarty KJ, Higgs NB, WoOdFord M, et al. 1985 Cisapride inhibits the secretory action of serotonin (5-HT) in mammalian small intestine. Gut 26:A 1111.

SMITh AN, VARMA JS 1984 The latency of the pudendo-anal reflex in man. Fournal of Physiology 360:49P.

Smout AJPM, BogaARD JW, Grade AC, et al. 1985 Effects of cisapride, a new gastrointestinal prokinetic substance, on interdigestive and postprandial motor activity of the distal oesophagus in man. Gut 26:246-251.

SNAPE WJ. ClaRke DD, Gautsch E 1985 Effect of cisapride on colonic smooth muscle in vivo and in vitro. Gastroenterology 88:1592.

STACHER G, SteINRINGER H, SCHNEIDER C, et al. 1986 Effects of cisapride on jejunal motor activity in fasting healthy humans. Gastroenterology 90:1210-1216.

ThOMFORDE GM, ZINSMEISTER AR, Brown ML, et al. 1985 Effects of cisapride (cis) and metoclopramide (met) on fed gastrointestinal motility and transit in a chronic dog model. Gastroenterology 88:1613.

VARMA JS, SMITH AN 1986 Reproducibility of the proctometrogram. Gut 27:288-292.

VARMA JS, BINNIE N et al. 1986 Differential effects of sacral anterior root stimulation on anal sphincter and colorectal motility in spinally injured man. British fournal of Surgery 73: 478482.

VARMA JS, SMITH AN 1984 Anorectal profilometry with the microtransducer. British fournal of Surgery 71:867-869.

Van Nueten JM, Leysen JE, Niemegeers CJE, et al. 1985 Cholinergic vs anti-dopaminergic properties of prokinetic substituted benzamides with gastrointestinal prokinetic activity. Gastroenterology 88:1623.

WIENBECK M, CUder-W IEsinger E, Berges W 1984 Cisapride acts as a motor stimulator in the human oesophagus. Gastroenterology 85:1298.

Wood JD, 1981 Physiology of the Enteric Nervous System. Chapter 1. Physiology of the Gastrointestinal Tract, Ed. Johnson LR. Raven Press, New York. 